\title{
A PEDAGOGIA TRANSLÍNGUE E A ELABORAÇÃO DE TAREFAS NA FORMAÇÃO INTEGRAL DO EDUCANDO BRASILEIRO
}

\author{
Anamaria Welp ${ }^{1 \times}$ \\ ${ }^{1}$ Universidade Federal do Rio Grande do Sul, RS, Porto Alegre, Brasil \\ Ofelia García ${ }^{2 * *}$ \\ ${ }^{2}$ City University of New York, NY, United States
}

\begin{abstract}
Resumo
O presente artigo procura propor um modelo de aplicação prática da pedagogia translíngue e oferecer uma contribuição dirigida ao aluno da educação básica brasileira, oportunizando o desempenho de tarefas através do inglês e do português, de maneira decolonial, e vinculando os entendimentos linguísticos emergentes em sala de aula aos conhecimentos conceituais que surgem a partir de tarefas colaborativas. Partindo da noção de língua como repertório (GARCÍA; WEI, 2015; BUSCH, 2015), propomos uma reflexão sobre os encadeamentos da teoria translíngue (GARCÍA, 2009; GARCÍA; WEI, 2015; GARCÍA; JOHNSON; SELTZER, 2017) na educação linguística, buscando apresentar os pontos convergentes entre a translinguagem e o aprendizado com base em tarefas.

Palavras-chave: Repertório Linguístico; Pedagogia Translíngue; Educação Linguística; Aprendizagem com Base em Tarefas
\end{abstract}

\section{TRANSLANGUAGING PEDAGOGY AND TASK DESIGN IN THE BRAZILIAN STUDENT'S INTEGRAL EDUCATION}

\section{Abstract}

The present paper proposes a model for the practical application of translanguaging pedagogy and offers a contribution for the Brazilian

\footnotetext{
"Professora associada na Universidade Federal do Rio Grande do Sul (UFRGS). Atua no curso de Graduação em Letras e no Programa de Pós-Graduação em Letras, na linha de pesquisa em Linguística Aplicada. Seus principais interesses de pesquisa são nas áreas de formação de professores, produção de material didático para a educação linguística, políticas linguísticas, internacionalização e educação bilíngue. Realizou estágio pós-doutoral na Universidad de Málaga, pela Fundación Carolina, e no Programa de Pós-Graduação da City University of New York, pela Comissão Fulbright. Atualmente é coordenadora do projeto interdisciplinar Letras Português-Inglês do Programa de Residência Pedagógica na UFRGS e editora-chefe da Revista Bem Legal www. ufrgs.br/revistabemlegal. E-mail: anamaria.welp@ufrgs.br. Orcid: http://orcid.org/0000-0002-9015-4761.

** Professora Emérita nos programas de doutorado em Educação Urbana e Culturas Latino-Americanas, Ibéricas e Latinas no Centro de Pós-Graduação da City University of New York. Tem publicado amplamente nas áreas de bilinguismo/multilinguismo e educação bilíngue, educação linguística, política linguística e sociologia da linguagem. Recebeu três prêmios da American Educational Research Association: Realização de Pesquisa vitalícia - Contribuições Distintas para Contextos Sociais na Educação (2019), Educação Bilíngue (2017) e Liderança de Aquisição de Segunda Língua através de Pesquisa (2019). É membro da Academia Nacional de Educação dos EUA. Para mais, visite www.ofeliagarcia.org. E-mail: ogarcia@gc.cuny.edu. Orcid: http://orcid. org/0000-0002-1405-9965.
} 
basic education student, by decolionally providing opportunities for task performance through English and Portuguese and linking emerging linguistic understandings in the classroom to conceptual knowledge arising from collaborative tasks. Drawing on the notion of language as a repertoire (GARCÍA; WEI, 2015; BUSCH, 2015), we propose a reflection on the implications of the translanguaging theory (GARCÍA, 2009; GARCÍA; WEI, 2015; GARCÍA; JOHNSON; SELTZER, 2017) for language education, and present the converging points between translanguaging and task-based learning.

Keywords: Language repertoire; Translanguaging Pedagogy; Language Education; Task-Based Learning 


\section{Introdução}

Em um voo internacional, duas crianças de cerca de quatro anos, sentadas nos assentos das fileiras do meio, desenham, cada uma em sua folha de papel sobre sua mesinha de refeições. Ao seu lado, na ponta direita, está sua mãe, e, na ponta esquerda, seu avô. Quando as duas crianças se dirigem à mãe, usam o inglês; quando falam com o avô, o português; e, quando interagem entre si, o francês é a língua escolhida. A cena desperta a atenção de todos os passageiros à volta. Uma comissária de bordo, encantada com o que vê e ouve, se aproxima da família e, tomada pela curiosidade, puxa conversa com uma das crianças: "Que lindo! Fala alguma coisa para mim em francês, vai!". A criança alvo da pergunta olha confusa para a comissária sem entender o que ela está pedindo. Não porque não entende a língua usada pela comissária, mas porque provavelmente não sabe o que ela quer dizer com aquele pedido.

A narrativa descrita acima, vivida por uma das autoras deste texto, é uma ilustração de como funciona a mente de uma pessoa bilíngue ${ }^{1}$. Vistas de fora, as práticas de linguagem das duas crianças de nossa narrativa nos remetem à presença de línguas separadas: inglês, francês e português. Entretanto, do ponto de vista das crianças, não há essa separação. Na mente de nossos pequenos protagonistas, o que há é um repertório semiótico, que se ajusta e se adapta às exigências do contexto, permitindo a interação com outras pessoas em diferentes situações. Quando a comissária pede que a criança fale em francês, ela está vendo o bilinguismo de fora. A criança, por sua vez, não sabe dizer o que é "falar em francês". Ela só sabe que, quando se dirige a sua mãe, seu irmão ou seu avô, sua fala deve se ajustar à interlocução.

Otheguy (2016, prefácio, p. x) explica que pessoas bilíngues "têm duas línguas apenas do ponto de vista social. Do seu ponto de vista [individual], elas têm apenas uma". O autor afirma que, quando vemos o prefixo bi-, de bilíngue, supomos a existência de duas línguas; quando nos deparamos com o prefixo multi-, de multilíngue, imaginamos várias línguas nomeadas ${ }^{2}$, como por exemplo, português, inglês, francês, etc. Em ambos os casos, pressupomos línguas separadas. Não nos ocorre que, na mente de uma pessoa bilíngue, as línguas não estão compartimentalizadas em "caixinhas" separadas, com fronteiras sociais e políticas claramente estabelecidas.

Como parte do projeto de pesquisa intitulado Investigação, análise e elaboração de tarefas pedagógicas para o ensino de línguas, desenvolvido em uma universidade pública do sul do Brasil, este artigo procura oferecer uma reflexão sobre a pedagogia translíngue e argumentar sobre seus encadeamentos no aprendizado com base em tarefas na educação linguística. Iniciamos descrevendo a perspectiva que vê a língua como repertório. Em seguida, introduzimos o conceito de translinguagem e apontamos suas implicações para a educação linguística. Então, explicamos como essa abordagem apresenta pontos convergentes com o aprendizado com base em tarefas. Por fim, apresentamos uma proposta de unidade didática contendo tarefas que se alinham à pedagogia translíngue. Nossa inten- 
ção é oferecer uma contribuição dirigida ao aluno da educação básica brasileira, oportunizando o trabalho através do inglês e do português e vinculando os entendimentos linguísticos emergentes aos conhecimentos conceituais que surgem a partir de tarefas colaborativas em sala de aula.

\section{Os repertórios linguísticos e o linguar dos sujeitos bilíngues}

Segundo García (2009), indivíduos bilíngues "lingueiam"3 de diferentes formas e têm experiências diversas com cada língua. Entretanto, se olharmos o processo pela perspectiva interna da pessoa bilíngue, o que se observa é um repertório, que reflete todas as vivências e os contextos experimentados por essa pessoa e as práticas linguísticas que os perpassam em diferentes momentos de sua existência.

Gumperz (1964), o primeiro que conceituou o termo, explica que repertório linguístico consiste no conjunto de recursos, incluindo línguas, dialetos, registros e rotinas, que utilizamos para interagir nas diversas situações em que nos encontramos na vida diária. Inicialmente, Gumpertz (1964) descreveu o fenômeno como algo relativamente estável, pertencente a uma comunidade discursiva. Entretanto, com as crescentes mudanças na vida contemporânea, fruto, entre outros fenômenos, da globalização, da expansão do acesso à tecnologia e dos movimentos migratórios, o conceito de repertório não mais cabe naquele cunhado pelo autor.

Alguns autores têm lançado mão de um conceito de repertório mais alinhado à contemporaneidade e adotado uma perspectiva biográfica, que leva em conta a trajetória de vida dos sujeitos (GARCÍA, 2009; BLOMMAERT; BACKUS, 2013; BUSCH, 2015; GARCÍA; WEI, 2015). Alinhados a essa noção, García e Wei (2015) afirmam que a linguagem não é um sistema simples de estruturas que independe das ações humanas em relação ao outro, de nosso existir em relação ao outro. Nesse sentido, o termo linguar é usado para se referir ao contínuo processo simultâneo de nos tornarmos nós mesmos e de, ao mesmo tempo, desenvolvermos nossas práticas linguísticas, à medida que interagimos e fazemos sentido no mundo.

A perspectiva de repertório linguístico de Busch (2015) ultrapassa o campo das ideologias de linguagem e reflete a experiência vivida através da linguagem. Assim, para a autora, a noção de repertório linguístico se constitui a partir da articulação de três frentes: interacional, pós-estruturalista e fenomenológica. Do ponto de vista interacional, a visão proveniente da antropologia da linguagem e da linguística interacional observa o sujeito a partir da interação linguística e social com os outros. Em uma perspectiva pós-estruturalista, examina o sujeito como constituído por discursos históricos e políticos. Enfim, o entendimento fenomenológico investiga o sujeito levando em conta os pré-requisitos corporais e emocionais para expressar e vivenciar a linguagem.

Portanto, se adotamos uma perspectiva de repertório linguístico para descrevermos as práticas de linguagem de pessoas bilíngues, não faz sentido falarmos em línguas nomeadas. Daí a explicação para o que ocorre na narrativa trazida na introdução deste artigo. 


\section{Do linguar ao translinguar}

Partindo dos conceitos de repertório linguístico e linguar, chegamos a uma forma diferente de ver e descrever as práticas linguísticas de pessoas bilíngues. Nesse prisma, segundo García e Wei (2015), o termo translinguagem traduz as complexas práticas linguísticas de sujeitos bilíngues, as quais carregam aspectos corporais e vivenciais e expressam diferentes contextos sociais e semióticos, transformando-os em recursos móveis dinâmicos para se adaptarem a situações sociolinguísticas globais e locais.

Inicialmente cunhado por Cen Williams (GARCÍA; WEI, 2015), no País de Gales, para se referir às práticas linguísticas que ocorriam em salas de aula bilíngues de língua galesa/inglesa em que os alunos alternavam línguas para construir sentido, desde a década de 1980, o termo translinguagem vem crescendo em popularidade nos estudos sobre educação bilíngue (GARCÍA, 2009; CREESE; BLACKLEDGE, 2010; CENOZ; GORTER, 2020; TIAN et al., 2020). A concepção de translinguagem indica uma mudança na forma como o bilinguismo é considerado na pesquisa e no ensino.

García (2009, p. 45) entende translinguagem como "as práticas de linguagem dos sujeitos bilíngues na perspectiva dos próprios usuários, e não simplesmente (...) o uso da língua por sujeitos bilíngues ou o contato de sujeitos bilíngues da perspectiva da própria língua”. Hesson, Seltzer e Woodley (2014) definem o termo como qualquer circunstância em que o aluno bilíngue usa práticas linguísticas familiares para promover sua aprendizagem. Otheguy, García e Reid (2015) descrevem a translinguagem como o uso do repertório linguístico completo de um falante sem os limites políticos e sociais de línguas nomeadas.

Avançando e ampliando a discussão, García (2019) afirma que a divisão, ou separação, das línguas de um indivíduo bilíngue é uma construção social empreendida por potências ocidentais, uma herança histórica e cultural imposta pelas escolas idealizadas pelas classes dominantes, que têm por finalidade consolidar o poder e criar indivíduos governáveis, sujeitos a normas e costumes imperialistas e colonizadores. Em contraste, como um convite a questionar essa noção herdada e monolítica de língua, a translinguagem oferece uma visão que expressa o dinamismo das práticas linguísticas dos falantes. Tal noção traz implicações importantes para o ensino e aprendizagem de línguas.

\section{A translinguagem e as implicações para a educação linguística}

Até hoje, os estudos acerca da educação linguística têm se ancorado em uma perspectiva monoglóssica. Nesse entendimento, as línguas de um indivíduo bilíngue são consideradas isoladas umas das outras, como se estivessem armazenadas em compartimentos separados no cérebro (GARCÍA; SYLVAN, 2011). Partindo-se da noção de língua como repertório, a translinguagem reflete uma visão heteroglóssica de língua. 
Di Fanti (2003) explica que a heteroglossia é um termo utilizado por Bakhtin para falar do romance, mas também do discurso, que traduz a sua concepção de língua com um caráter dinâmico, que não se constitui unitariamente, mas sim como uma arquitetura de vozes discursivas/sociais. Assim, numa perspectiva heteroglóssica, as línguas são múltiplas e coexistentes, e a ideia de uma só possibilidade, como a de uma "língua padrão", "culta", que não considera as variedades, é rejeitada.

Uma das grandes vantagens da pedagogia translíngue vem do fato de se fazer uso das práticas que são naturalmente recorrentes entre pessoas bilíngues, dentro e fora de sala de aula, ou seja, no cotidiano ou nos contextos de ensino e aprendizagem. Dessa forma, tanto a teoria quanto à pedagogia translíngues partem da observação de tais práticas. Na educação linguística, a sala de aula translíngue contempla as várias formas pelas quais sujeitos bilíngues selecionam recursos de seus repertórios de forma estratégica para se fazer entender e para construir significados (GARCÍA, 2009). Nesse contexto, a translinguagem é uma teoria que parte da prática. Uma sala de aula translíngue é um espaço

em que os alunos usam todo o seu repertório linguístico e não somente a língua específica que é usada para propósitos instrucionais. Esse tipo de sala de aula pode ser ministrado em qualquer lugar onde se encontram alunos bilíngues ou que estão se tornando bilíngues (GARCÍA; JOHNSON; SELTZER, 2017, p. 1).

A pedagogia translíngue, portanto, incentiva o aluno a se tornar mais consciente de seu potencial expressivo e de seu poder de escolhas sobre a língua. Ao permitir que o aluno use todas as características de seu repertório linguístico, "incluindo léxico (palavras), sintaxe (gramática) e discurso (agrupamentos maiores de texto) para fazer conexões e comparações, fazer perguntas profundas e praticar e brincar com a língua" (GARCÍA; JOHNSON; SELTZER, 2017, p. 11), a pedagogia translíngue permite que o aluno se engaje em atividades significativas. Dessa forma, segundo García (2019, p. 7), “o objetivo das práticas pedagógicas translíngues é libertar os sistemas de signos que foram restringidos pela dominação sociopolítica, tentando dar voz a todos e corrigir os diferenciais de poder entre os falantes". Nesse contexto, ao contrário do que ocorre nas pedagogias monoglóssicas, que priorizam o que falta ao educando, por limitar suas práticas linguísticas ao uso de uma só língua ou de um só padrão, a pedagogia translíngue valoriza o que o educando tem, encorajando-o a usar toda a gama de seu repertório linguístico em sala de aula para construir sentido ou produzir textos de gêneros escolares/acadêmicos.

García, Johnson e Seltzer (2017) afirmam que a pedagogia translíngue contém quatro propósitos: (1) apoiar os alunos enquanto eles se envolvem e compreendem conteúdos e textos complexos; (2) fornecer oportunidades para os alunos desenvolverem práticas linguísticas para contextos acadêmicos; (3) abrir espaço para o bilinguismo e as formas de conhecimento dos alunos; e (4) apoiar o desenvolvimento socioemocional e as identidades bilíngues dos alunos. Esses 
propósitos devem fazer parte das crenças do professor e formar o que as autoras denominam corriente: um constante fluxo no uso das práticas linguísticas presentes em sala de aula.

Ao se alinhar a essa perspectiva, o professor deve ter em mente as três vertentes da corriente translíngue: stance, design e shift'. Stance diz respeito à crença do professor de que o aluno possui um repertório linguístico abrangente e à sua forte orientação voltada à justiça social. Design se refere ao planejamento cuidadoso da instrução, que permite que o professor trabalhe dentro da corriente translíngue e aborde os quatro propósitos dessa pedagogia. Shift concerne à adaptação momento a momento das práticas do professor para se adequar às práticas linguísticas dos seus alunos, mesmo que signifique sair do seu planejamento original para seguir a corriente translíngue mais livremente.

\section{A translinguagem e o ensino por tarefas}

Neste artigo, adotamos a seguinte definição de tarefa pedagógica: uma tarefa é uma motivação para usar a língua com um propósito social de maneira situada. Como tal, deve projetar um interlocutor, uma prática social e o uso adequado de recursos linguísticos. Assim como Van Den Branden (2006), é nosso entendimento que o aprendizado com base em tarefas consiste em uma abordagem estratégica de projetar e organizar a prática pedagógica para estimular e apoiar os alunos a atingir os objetivos de aprendizagem. Segundo Welp, Didio e Finkler (2019),

o ensino por tarefas se configura como a abordagem mais sintonizada com o momento em que vivemos por dois motivos. Em primeiro lugar, (...) oferece oportunidades de aprendizado nas quais a complexidade total do uso da língua pode ser experimentada em condições reais. Em segundo, promove a interação em torno do trabalho exploratório compartilhado e a reflexão sobre as formas linguísticas a serem usadas para criar mensagens significativas. (WELP; DIDIO; FINKLER, 2019 , p. 5)

Conforme Van den Branden (2016), o aprendizado com base em tarefas promove a educação linguística através do uso da língua. Assim, entendemos que, por oferecer oportunidades de participação em diferentes práticas sociais e, portanto, de expansão dos repertórios dos educandos, essa abordagem se alinha à pedagogia translíngue. Ao desempenhar tarefas em uma aula translíngue, os alunos se sentem confiantes para ler, escrever, explorar temas, negociar significados, solucionar problemas e se expressar lançando mão de todo seu repertório linguístico.

Seals et al. (2020, p. 281) fazem uma análise comparativa entre os princípios orientadores do aprendizado com base em tarefas e da pedagogia translíngue e indicam os pontos de convergência das duas abordagens. Entre os elementos assinalados pelos autores estão o trabalho colaborativo entre os alunos, a integração entre língua e conteúdo e o caráter experiencial e dinâmico do aprendizado. 
Podemos somar a isso a fluidez com que o trabalho pedagógico e as práticas linguísticas acontecem no desempenho das tarefas e, conforme García e Sylvan (2011), a atenção à singularidade das experiências individuais que constituem uma pluralidade em sala de aula.

\section{O planejamento do trabalho pedagógico através das lentes da translinguagem}

Nesta seção, apresentamos uma proposta de unidade didática contendo tarefas desenhadas sob a perspectiva translíngue. O trabalho proposto é voltado a jovens adolescentes que estejam cursando o ensino médio, sobretudo na rede pública de educação básica. Para dialogar com esse público, foi escolhido um tema que tem sido discutido em diversos contextos: mudanças climáticas. A escolha do tema se deu fundamentalmente em razão do ativismo da adolescente sueca Greta Thunberg, que tem ganhado o mundo a partir de seus discursos e de suas ações em defesa do meio ambiente. Além disso, jovens nessa etapa do ensino básico potencialmente se identificam com a adolescente ativista por serem da mesma geração e pelo fato de Greta utilizar a mesma linguagem de indivíduos dessa faixa etária. Além disso, o tema é consonante às orientações da Base Nacional Comum Curricular (BNCC) (BRASIL, 2018), conforme as "Competências Específicas de Ciências Humanas e Sociais Aplicadas para o Ensino Médio" (p. 570), é indiscutivelmente relevante para o futuro do planeta e deve ser abordado entre as gerações mais jovens.

Cabe salientar que a proposta tem como foco principal estudantes da educação básica brasileira, falantes do português, que estão se tornando bilíngues e cujos repertórios se encontram em diferentes pontos do continuum do bilinguismo, o que é bastante comum em aulas de línguas e que normalmente representa um desafio para professores. A intenção é colocar o aluno em primeiro lugar, oferecendo uma contribuição que vai além da educação bilíngue, ou do ensino de uma língua adicional, ou até mesmo da integração de língua e conteúdo.

Ainda, a unidade didática não se destina ao ensino de somente um idioma ou de um componente curricular em específico, mas foi planejada segundo a teoria translíngue, para o trabalho pedagógico através do inglês e do português, sob uma perspectiva decolonial. Decolonial aqui é entendido como de natureza dialógica, que valoriza os repertórios diversos e os conhecimentos de todos os envolvidos no processo de aprendizagem. Ao valorizar as práticas linguísticas a partir dos sujeitos que as produzem, a translinguagem se configura como uma pedagogia decolonial, que humaniza e que promove o 'fazer juntos', buscando assim maneiras outras de ser, pensar e fazer a educação bilíngue. Como afirma Walsh (2018),

Estou pensando aqui em práticas, estratégias, metodologias e maneiras de fazer que se entrelaçam e que são construídas em resistência e oposição, bem como em insurgência, afirmação e reexistência (como reumanização), em imaginar e construir um mundo diferente. (WALSH, 2018, p. 88). 
Nesse sentido, a unidade didática proposta pretende que os alunos pensem além de componentes curriculares e que sejam educados em diferentes línguas e conteúdos para contextos interdisciplinares locais e globais. Nesse sentido, língua e conteúdo caminham juntos para uma formação integral do educando, num movimento dinâmico em que novos recursos da língua se desenvolvem juntamente com os já existentes no repertório do aluno e, ao mesmo tempo, com os entendimentos conceituais que emergem a partir do trabalho colaborativo.

Para o planejamento da proposta, adaptamos o Modelo de Planejamento de Unidade Translíngue sugerido por García, Johnson e Seltzer (2017, p. 175) para o contexto da educação básica brasileira. Assim, a unidade está organizada conforme o Quadro 1 abaixo:

Quadro 1 - Planejamento da Unidade Translíngue

\begin{tabular}{|c|c|c|}
\hline Perguntas essenciais & \multicolumn{2}{|c|}{$\begin{array}{l}\text { O que é mudança climática? } \\
\text { Quais os efeitos desse fenômeno no planeta? E na minha comunidade? } \\
\text { Por que devemos conhecer mais e discutir sobre o tema? }\end{array}$} \\
\hline $\begin{array}{l}\text { Competências } \\
\text { Específicas da BNCC }\end{array}$ & \multicolumn{2}{|c|}{$\begin{array}{l}\text { CIÊNCIAS HUMANAS E SOCIAIS APLICADAS PARA O ENSINO MÉDIO } \\
\text { 1. Analisar processos políticos, econômicos, sociais, ambientais e culturais nos } \\
\text { âmbitos local, regional, nacional e mundial em diferentes tempos, a partir da } \\
\text { pluralidade de procedimentos epistemológicos, científicos e tecnológicos, de } \\
\text { modo a compreender e posicionar-se criticamente em relação a eles, conside- } \\
\text { rando diferentes pontos de vista e tomando decisões baseadas em argumentos e } \\
\text { fontes de natureza científica. } \\
\text { 2. Participar do debate público de forma crítica, respeitando diferentes posições } \\
\text { e fazendo escolhas alinhadas ao exercício da cidadania e ao seu projeto de vida, } \\
\text { com liberdade, autonomia, consciência crítica e responsabilidade. }\end{array}$} \\
\hline $\begin{array}{l}\text { Objetivos de conteúdo } \\
\text { e de língua }\end{array}$ & $\begin{array}{l}\text { Objetivos de conteúdo } \\
\text { - Compreender o conceito de mu- } \\
\text { dança climática e suas consequências } \\
\text { para o planeta. } \\
\text { - Conhecer os elementos (números, } \\
\text { substâncias, fenômenos, etc.) que } \\
\text { afetam a temperatura no planeta. } \\
\text { - Relacionar os efeitos do aqueci- } \\
\text { mento global com ações no mundo e } \\
\text { na comunidade escolar. }\end{array}$ & $\begin{array}{l}\text { Objetivos de uso da língua } \\
\text { - Ler e compreender textos em inglês e } \\
\text { em português sobre o tema da unidade. } \\
\text { - Sintetizar seu entendimento sobre o } \\
\text { conteúdo dos textos nas duas línguas } \\
\text { usando a língua oral e a escrita. } \\
\text { - Posicionar-se criticamente e reagir } \\
\text { sobre o tema usando a língua oral e } \\
\text { escrita. }\end{array}$ \\
\hline Objetivos translíngues & \multicolumn{2}{|c|}{$\begin{array}{l}\text { - Desenvolver o bilinguismo através do contraste entre o uso de recursos em } \\
\text { textos em inglês e em português para a construção de sentido. } \\
\text { - Desenvolver a consciência linguística em relação à equivalência de termos em } \\
\text { inglês e em português. } \\
\text { - Trabalhar colaborativamente em grupos resolvendo problemas sobre o con- } \\
\text { teúdo e sobre a língua usando todo o repertório linguístico do grupo. } \\
\text { - Usar o inglês e o português para debater o conteúdo dos textos lidos e produ- } \\
\text { zir textos sobre o tema proposto. }\end{array}$} \\
\hline Produto final & \multicolumn{2}{|c|}{$\begin{array}{l}\text { - Criar cartazes em inglês e em português com mensagens de alerta sobre os } \\
\text { efeitos nocivos das mudanças climáticas no mundo e na sua comunidade. } \\
\text { - Realizar uma campanha bilíngue de conscientização sobre as mudanças } \\
\text { climáticas. }\end{array}$} \\
\hline
\end{tabular}

Fonte: As autoras (2021). 
A unidade inicia ativando o conhecimento prévio dos alunos em relação à Greta Thunberg. A primeira tarefa tem a finalidade de trazer à tona o que os alunos já conhecem sobre a ativista e descobrir outros fatos sobre ela através de sua biografia. Para tanto, são apresentadas biografias em inglês e em português para que os alunos tenham uma compreensão profunda dos textos, explorando -os através do uso de todo o seu repertório linguístico. Vale ressaltar que todas as tarefas da proposta apresentam suas instruções de forma bilíngue, fazendo uso da língua inglesa e da língua portuguesa lado a lado, alternadamente, para frisar que não há uma hierarquia entre as línguas a serem utilizadas em sala de aula. Além disso, as tarefas provocam a leitura dos textos nas duas línguas, promovendo assim o contraste entre elas e desenvolvendo a consciência linguística dos sujeitos bilíngues que estão emergindo em sala de aula.

\subsection{A unidade didática "climate change awareness campaign/ campanha de conscientização sobre mudanças climáticas”}

Quadro 2 - Tarefa I: Introducing the theme/Introduzindo o tema

\begin{tabular}{|l|l|}
\hline Discuss the questions below in small groups. & $\begin{array}{l}\text { Discuta as questões abaixo em pequenos } \\
\text { grupos. }\end{array}$ \\
\hline $\begin{array}{l}\text { 1) What do you know about climate change? } \\
\text { What do you think about it? }\end{array}$ & $\begin{array}{l}\text { 1) O que você sabe sobre mudanças climáticas? } \\
\text { Qual a sua opinião sobre o assunto? }\end{array}$ \\
$\begin{array}{l}\text { 2) Is there anything you do in your everyday } \\
\text { life to protect our planet? If so, name a few } \\
\text { actions you take. }\end{array}$ & $\begin{array}{l}\text { 2) Você faz alguma coisa no seu dia a dia para } \\
\text { proteger o nosso planeta? Se sim, liste algumas } \\
\text { dessas coisas. }\end{array}$ \\
$\begin{array}{l}\text { 3) Do you know anyone or any organization } \\
\text { that takes action concerning the environment? } \\
\text { If so, name them. }\end{array}$ & $\begin{array}{l}\text { 3) Você conhece alguma pessoa ou organização } \\
\text { meio ambiente? Se sim, cite-a(s). }\end{array}$ \\
\hline $\begin{array}{l}\text { Share the ideas discussed with the whole } \\
\text { group. }\end{array}$ & $\begin{array}{l}\text { Compartilhe com o grande grupo as ideias } \\
\text { discutidas. }\end{array}$ \\
\hline
\end{tabular}

Fonte: As autoras (2021).

Quadro 3 - Tarefa II: Conhecendo Greta Thunberg / Meeting Greta Thunberg Trabalho em grupos. Responda as perguntas $\quad$ Group work. Answer the questions below. abaixo.

1) Você conhece Greta Thunberg? Se sim, o que você sabe sobre ela?

2) Leia as biografias dela, em inglês e português, e confirme as informações.
1) Do you know Greta Thunberg? If so, what do you know about her?

2) Read her biographies, in English and Portuguese, and check your information. 


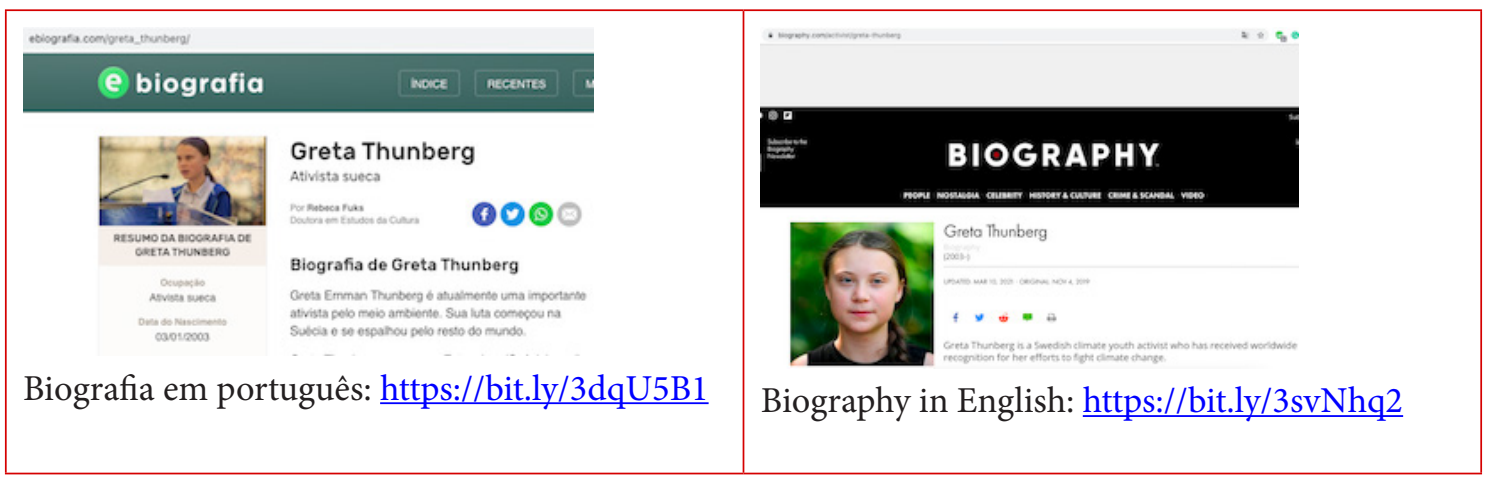

Fonte: As autoras (2021).

Quadro 4 - Tarefa III: Reacting to Greta's biography/Reagindo à biografia de Greta Work with your group. Read the texts in both languages again and answer the questions below. Try to include as much information as you can find. You can use any language in your answers.

Trabalhe com seu grupo. Leia os textos nas duas línguas novamente e responda as perguntas abaixo. Tente incluir o máximo de informações que puder encontrar. Você pode usar qualquer idioma nas suas respostas.

1) What do both biographies tell about her personal life? List the pieces of information?

2) How did she become famous?

3) What actions has she been taking to protect the environment?

4) Which pieces of information most called your attention in the biographies? Why?

Compare your group's answers with the class.
1) O que as duas biografias contam sobre sua vida pessoal? Liste as informações:

2) Como ela se tornou famosa?

3) Que iniciativas ela tem tomado em defesa do meio ambiente?

4) Quais informações mais chamaram sua atenção nas biografias? Por quê?

Compare as respostas do seu grupo com as da turma.

Fonte: As autoras (2021).

Após o término do trabalho com a biografia de Greta, é apresentada uma tarefa que introduz a próxima leitura: o discurso da ativista no Encontro de Cúpula sobre Ação Climática da Organização das Nações Unidas (ONU) em 2019. A fala de Greta ganhou projeção internacional e irritou muitos líderes conservadores, que resistem a tomar medidas contra o aquecimento global, principalmente pela forma contundente com que ela se dirigiu a todos os chefes de nação.

Esta parte da unidade inicia mais uma vez com uma tarefa que evoca os conhecimentos prévios dos alunos sobre o famoso discurso para, em seguida, levá-los a ler e compreender com profundidade seu conteúdo e a se posicionar criticamente sobre a leitura. Novamente, a proposta procura explorar o repertório linguístico completo dos alunos para que eles tenham um entendimento pleno 
sobre os fatos apresentados por Greta em seu discurso. Para facilitar o trabalho, a leitura do discurso é dividida em duas partes: as questões IV e $\mathrm{V}$ exploram a primeira parte do discurso, e a VI e a VII trabalham a segunda parte ${ }^{5}$.

Quadro 5 - Tarefa IV: Preparando-se para uma nova leitura /Preparing for a new reading

\begin{tabular}{|c|c|}
\hline Discuta com seu grupo. & Discuss with your group. \\
\hline $\begin{array}{l}\text { 1) Você sabia que Greta discursou no Encontro } \\
\text { de Cúpula sobre Ação Climática da ONU em } \\
2019 \text { ? Se sim, o que você sabe sobre o conteúdo } \\
\text { de sua fala? Se não, sobre o que você acha que } \\
\text { ela falou? } \\
\text { 2) Leia a primeira parte da transcrição do } \\
\text { discurso de Greta, em inglês ou em português, e } \\
\text { confirme suas ideias. }\end{array}$ & $\begin{array}{l}\text { 1) Did you know that Greta spoke at the U.N. } \\
\text { Climate Action Summit } 2019 \text { ? If so, what do you } \\
\text { know about the content of her talk? If not, what } \\
\text { do you think she talked about? } \\
\text { 2) Read the first part of Greta's speech transcript, } \\
\text { in English or in Portuguese, and check your } \\
\text { ideas. }\end{array}$ \\
\hline (i) ONU News $\mathrm{R}=\mathrm{m}$ & 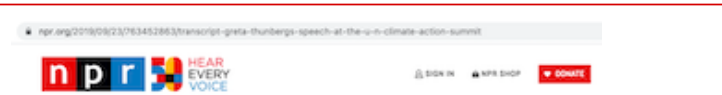 \\
\hline 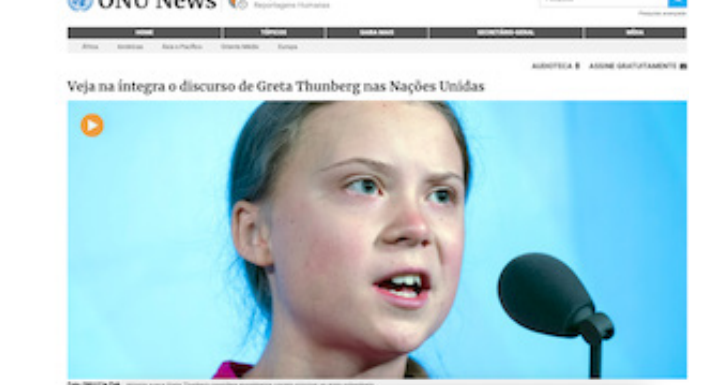 & $\begin{array}{l}\text { Transcript: Greta Thunberg's Speech At } \\
\text { The U.N. Climate Action Summit }\end{array}$ \\
\hline $\begin{array}{l}\text { O discurso de Greta em português: https://bit. } \\
\text { ly/32k30xU }\end{array}$ & Greta's speech in English: https://n.pr/3x2e1C0 \\
\hline
\end{tabular}

Fonte: As autoras (2021).

Quadro 6 - Tarefa V: Understanding the text/Entendendo o texto

\section{Read the text again and answer the questions} below with your group.

1) How does she feel about being there talking to world leaders?

2) What parts of her speech make you think that? Underline these parts in both versions of the text (in English and Portuguese).
Leia o texto novamente e responda as questões abaixo com o seu grupo.

1) Como ela se sente sobre estar lá, falando com líderes mundiais?

2) Que partes do discurso fazem você pensar isso? Sublinhe essas partes nas duas versões do texto (em inglês e português).

Compare your answer with your classmates'.

Fonte: As autoras (2021).

Quadro 7 - Tarefa VI: Preparando-se para a leitura da segunda parte do discurso de Greta/Preparing to read the second part of Greta's speech 
Trabalhe com seu grupo. Traduzam os trechos em inglês para o português e os em português para o inglês. Usem dicionários online ou aplicativos de tradução para ajudá-los.

Work with your group. Translate the passages in English to Portuguese and the ones in Portuguese to English. Use online dictionaries or translation apps to help you.

1) Entire ecosystems are collapsing:

2) below a 1.5 degrees global temperature rise:

3) fairy tales of eternal economic growth:

4) emissões de dióxido de carbono:

5) começo de uma extinção em massa:

6) retirar centenas de bilhões de toneladas de dióxido de carbono do ar:

Leiam as duas versões da segunda parte do dis- Read both versions of the second part of Greta's curso de Greta e verifiquem se as traduções de seu grupo são semelhantes ou diferentes das dos textos.

speech and check if your group's translations are similar or different from the ones in the texts.

Comparem suas respostas com as de seus

Compare your answers with your classmates'. colegas.

Fonte: As autoras (2021).

Quadro 8 -Tarefa VII: Reading the rest of Greta's talk/Lendo o restante da fala de Greta

The figures below refer to data presented by Greta in her speech to support her arguments. Read the second part of her speech, and write, next to each figure, which data it refers to. Then answer the questions that follow.
Os números abaixo se referem a dados apresentados por Greta em seu discurso para fundamentar seus argumentos. Leia a segunda parte de sua fala e escreva, ao lado de cada número, a que dado ele se refere. Então responda as perguntas que seguem.

30 years -

10 anos -

$50 \%$ -

1.5 degrees -

$67 \%$ -

420 toneladas giga -

2018 -

350 gigatons -

$8 \frac{1}{2}$ years -

Compare your answers with your classmates'.

Compare suas respostas com as de seus colegas. 
1) Which pieces of the information above most strike you? Why?

2) How do you think the world leaders reacted to her speech? What makes you say that?

3) What is your opinion about her speech? Do you think she should have addressed the world leaders differently? Explain your answer.

4) What actions do you think should be taken to stop climate change? Make a list with your group and then share it with the class.
1) Quais das informações acima mais o impressionam? Por quê?

2) Como você acha que os líderes mundiais reagiram ao discurso dela? $\mathrm{O}$ que o faz pensar isso?

3) Qual a sua opinião sobre o discurso dela? Você acha que ela deveria ter se dirigido aos líderes mundiais de outra forma? Explique sua resposta.

4) Que ações você acha que podem ser tomadas para parar as mudanças climáticas? Faça uma lista com seu grupo e depois compartilhe-a com a classe.

Fonte: As autoras (2021).

Nesta parte da unidade, o trabalho pedagógico encaminha os alunos à ação. Como forma de promover uma reação ao que leram e discutiram, os alunos são instigados a serem ativistas contra as mudanças climáticas e agirem em favor da preservação do meio ambiente. São então convidados a desenvolver uma campanha bilíngue a ser divulgada na comunidade escolar através da confecção de cartazes a serem expostos nos espaços da escola onde há bastante visibilidade.

Caso a escola disponha de recursos, como um laboratório de informática com conexão à Internet, como alternativa, o professor pode propor que a campanha circule no Instagram uma vez que, além de a rede social ser familiar à maioria dos jovens, é também utilizada por muitos com frequência. Além disso, a publicação na rede social leva a produção dos alunos para além dos muros da escola e abre possibilidades de interlocução com diferentes sujeitos, falantes das línguas utilizadas na tarefa. Cabe destacar que, durante as atividades desenvolvidas em sala de aula, os alunos são estimulados ao trabalho colaborativo, explorando o tema através da leitura, do debate, da construção de significados e da utilização de todo seu repertório linguístico através da atividade em grupos.

Quadro 9 - Tarefa VIII: Acting for climate change awareness/Agindo para a conscientização sobre as mudanças climáticas

Group work. Your group is going to design a Trabalho em grupo. Seu grupo vai criar uma bilingual campaign (English and Portuguese) for climate change awareness to be advertised around the school. Think of all possible actions you can take to boost the campaign. Make a list. You may use any language you want. Look at the pictures below with posters to get inspired. campanha bilíngue (inglês e português) para conscientização sobre mudanças climáticas a ser divulgada nos espaços da escola. Pensem em todas as ações possíveis que vocês podem desempenhar para impulsionar a campanha. Façam uma lista. Vocês podem usar a língua que quiserem. Olhem as imagens abaixo com posters para se inspirarem. 


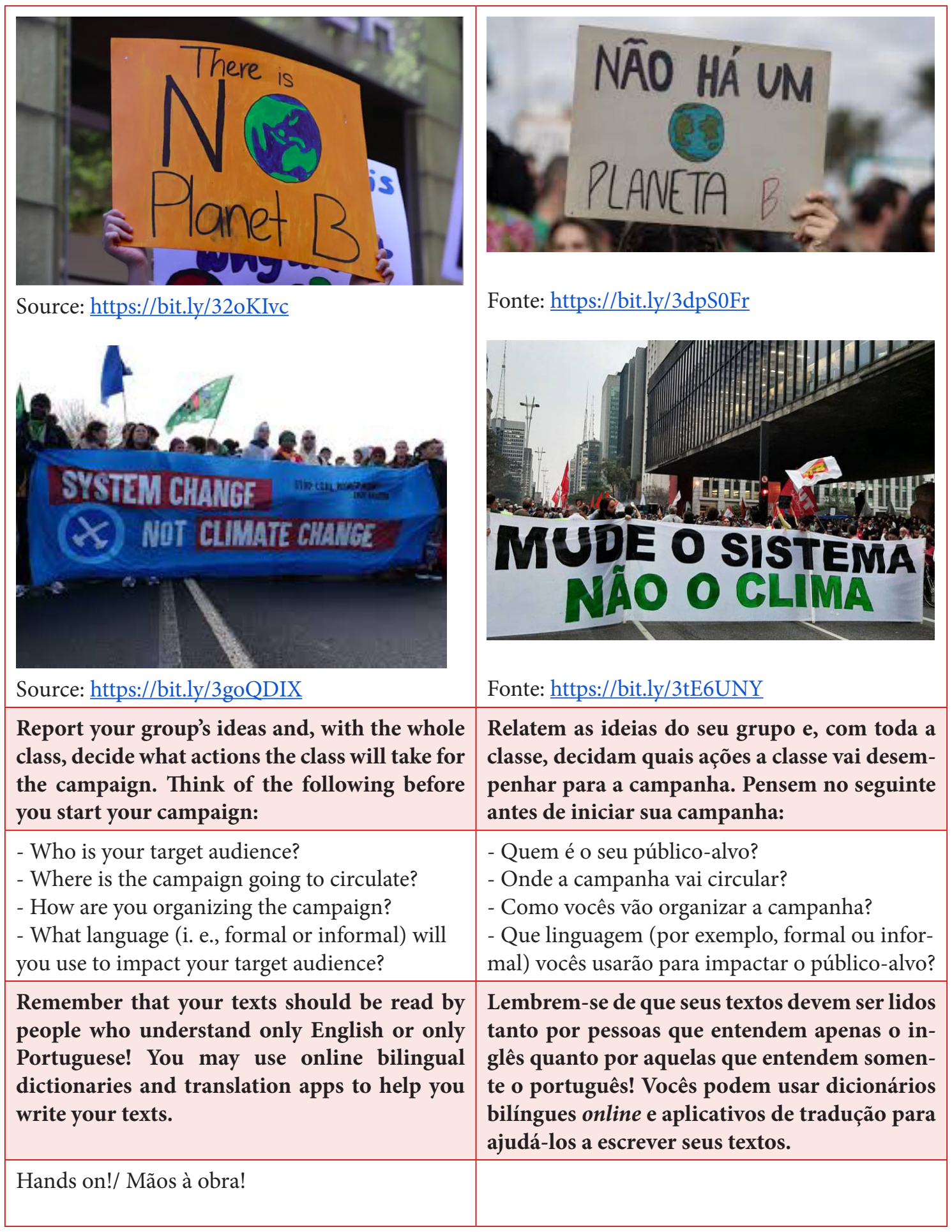

Fonte: As autoras (2021).

Cabe destacar que a proposta aqui apresentada tem o propósito de oferecer uma sugestão de unidade didática e não pretende esgotar a discussão e a reflexão sobre o tema abordado. Portanto, evidentemente, caso o professor deseje aprofundar o estudo sobre mudanças climáticas com seus alunos, pode ampliar a sequência didática através da inclusão de outros textos, como por exemplo o Acordo de Paris ${ }^{6}$ ou algum artigo publicado sobre as consequências do aquecimento global. 


\section{Considerações finais}

Este artigo teve por finalidade propor uma reflexão sobre a pedagogia translíngue. Para tanto, buscou argumentar sobre suas implicações no aprendizado com base em tarefas na educação linguística. Partindo da noção de língua como repertório, procuramos mostrar nosso alinhamento à perspectiva biográfica de repertório (GARCÍA; WEI, 2015; BUSCH, 2015) e à visão heteroglóssica de língua, que prioriza o repertório linguístico dos sujeitos bilíngues, sem a separação das línguas que o compõem de forma hierárquica ou política.

Apresentamos também nosso entendimento de aprendizado com base em tarefas e de o que vem a ser uma tarefa pedagógica: uma motivação para usar a língua, com interlocutores definidos e com um propósito social, de maneira situada. Tentamos mostrar os aspectos em comum dessa abordagem e da pedagogia translíngue, entre eles, a natureza colaborativa das duas perspectivas, a integração entre língua e conteúdo, o caráter experiencial e dinâmico que ambas promovem (SEALS et al., 2020), a fluidez das práticas linguísticas que oportunizam em sala de aula e a atenção à singularidade na pluralidade (GARCÍA; SYLVAN, 2011), pois cada sujeito possui um repertório singular, mas os repertórios de todos se complementam no trabalho conjunto em uma sala de aula onde a diversidade é acolhida.

Da mesma forma, procuramos demonstrar, através de uma proposta de unidade didática, como é possível ir além da educação bilíngue, do ensino de uma língua adicional, ou até mesmo da integração de língua e conteúdo. Sob as lentes da teoria translíngue e alinhadas a uma perspectiva decolonial, partimos da língua para os sujeitos, buscando derrubar fronteiras entre componentes curriculares. Procuramos, assim, oferecer uma contribuição para a educação integral de jovens brasileiros, falantes de português, cursando a escola básica.

Reforçamos que, embora a unidade didática esteja pronta para ser aplicada pelo professor, em uma aula ministrada segundo a pedagogia translíngue, é imprescindível que a corriente (GARCÍA; JOHNSON; SELTZER, 2017) esteja em atividade e que o professor tenha consciência de seu papel na condução das tarefas. Portanto, ele deve estar sensível às práticas linguísticas dos alunos ao desempenhar as tarefas e deve estar à vontade para mudar o curso ou adaptar trechos da unidade caso seja necessário. Assim, stance, design e shift devem estar em pleno funcionamento para permitir que a translinguagem aconteça de forma natural e exitosa, valorizando todas as práticas linguísticas presentes. Dessa forma, o repertório de cada aluno é bem-vindo e prestigiado, ao contrário do que ocorre em salas de aula onde determinados usos das línguas dos sujeitos são inibidos.

Notas

1. Em consonância com García (2009) e García, Johnson e Seltzer (2017), neste artigo, utilizaremos o termo bilíngue para nos referir a indivíduos que falam duas ou mais línguas. 
2. As línguas nomeadas são uma construção social, que reflete a visão externa do repertório de um indivíduo bilíngue. Em contraste, na perspectiva do próprio falante bilíngue, há somente uma língua em seu repertório particular, sem divisões políticas ou hierárquicas.

3. García e Wei $(2015$, p. 8) utilizam o termo laguaging. A tradução do termo para o português é inexistente, portanto, as autoras optaram por utilizar "linguar" e flexionar como verbo regular da primeira conjugação.

4. Optamos por manter as palavras originais em espanhol - corriente - e em inglês stance, design e shift - utilizadas pelas autoras para não correr o risco de perder seu sentido na tradução.

5. Sugerimos que, ao trabalhar os textos em inglês e em português, o professor dividaos da seguinte forma: a primeira parte do texto em inglês deve ir até a linha 14, e a primeira parte do texto em português deve ir até a linha 17, conforme as versões aparecem em cada site; a segunda parte, portanto, deve conter o restante dos textos das duas versões.

6. Disponível em diversas línguas em https://www.consilium.europa.eu/en/policies/ climate-change/paris-agreement/. Acesso em 16 de maio de 2021.

\section{Referências}

BLOMMAERT, J.; BACKUS, A. Superdiverse repertoires and the individual. In: SAINT-JACQUES, I.; WEBER, J. (Eds.). Multilingualism and multimodality: current challenges for educational studies. Rotterdam: Sense Publishers, 2013, p. 11-32.

BRASIL. Base nacional comum curricular. Brasília: Ministério da Educação, 2018.

BUSCH, B. Expanding the Notion of the Linguistic Repertoire: on the concept of spracherleben - the lived experience of language. Review of Applied Linguistics. Volume 38, Issue 3, Junho 2015, p. 340-358.

CENOZ, J.; GORTER, D. Teaching English through pedagogical translanguaging. World Englishes, 39(2), 2020, p. 300-311. https://doi.org/10.1111/weng.12462

CREESE, A.; BLACKLEDGE, A. Translanguaging in the bilingual classroom: a pedagogy for learning and teaching?. The Modern Language Journal, 94, i, 2010, p. $103-115$.

DI FANTI, M. G. C. A linguagem em Bakhtin: pontos e pespontos. Veredas - Rev. Est. Ling, Juiz de Fora, v.7, n.1 e n.2, jan./dez. 2003, p. 95-111.

GARCÍA, O. Bilingual education in the 21 st century: a global perspective. Malden, MA: Blackwell, 2009.

GARCÍA, O. Decolonizing foreign, second, heritage and first languages. In: MACEDO, D. (Ed.) Decolonizing foreign language education: The misleading of English and other imperial languages. (pp.152-168). New York: Routledge, 2019, p. 152-168.

GARCÍA, O.; JOHNSON, S. I.; SELTZER, K. The translanguaging classroom: leveraging student bilingualism for learning. Philadelphia, PA: Caslon, 2017.

GARCÍA, O.; SYLVAN, C. E. Pedagogies and practices in multilingual classrooms: singularities in pluralities. Modern Language Journal, 95(3), 2011, p. 385-400. https://doi. org/10.1111/j.1540-4781.2011.01208.x

GARCÍA, O.; WEI, L. Translanguaging: language, bilingualism and education. Basingstoke, UK: Palgrave Macmillan, 2015. 
GUMPERZ, John J. Linguistic and social interaction in two communities. American Anthropologist 66 (6): 1964, p.137-153. https://doi.org/10.1525/aa.1964.66. suppl_3.02a00100

HESSON, S.; SELTZER, K.; WOODLEY, H. H. Translanguaging in curriculum and instruction. New York, NY: CUNY-NYSIEB, 2014.

OTHEGUY, R. Prefácio. In.: GARCÍA, O.; KLEYN, T. (Eds.) Translanguaging with multilingual students: learning from classroom moments. New York: Routledge, 2016.

OTHEGUY, R.; GARCÍA, O.; REID, W. Clarifying translanguaging and deconstructing named languages: a perspective from linguistics. Applied Linguistics Review 6(3): 2015, p. 281-307.

SEALS, C. A.; NEWTON, J.; ASH, M.; NGUYEN, B. T. T.. Translanguaging and task-based language teaching: crossovers and challenges. In: TIAN, Z; AGHAI, L; SAYER, P.; SCHISSEL, J. L.. (Eds.) Envisioning TESOL through a translanguaging lens. Educational Linguistics 45, Switzerland: Springer, 2020, p. 275-292. https://doi.org/10.1007/978-3-030-47031-9_13

TIAN, Z.; AGHAI, L; SAYER, P.; SCHISSEL, J. L. Envisioning TESOL through a translanguaging lens. Educational Linguistics 45, Switzerland: Springer, 2020, p. 275-292. https://doi.org/10.1007/978-3-030-47031-9_13

VAN DEN BRANDEN, K. Task-based language teaching. In: HALL, G. (Ed.). The Routledge Handbook of English Language Teaching. London: Routledge, 2016, p. 238-251.

WALSH, C. E. Interculturality and Decoloniality. In: MIGNOLO, Walter D.; WALSH, Catherine E. (Eds.) On decoloniality: concepts, analytics, praxis. Durham, NC: Duke University Press, 2018, p. 57-80.

WELP, A. K. S.; DIDIO, A. R.; FINKLER, B.. Questões contemporâneas no cinema e na literatura: o desenho de uma sequência didática para o ensino de inglês como língua adicional. Brazilian English Language Teaching Journal, Porto Alegre, v. 10, n. 2, 2019, p. 1-25. DOI: https:// doi.org/10.15448/2178-3640.2019.2.35861.

Recebido em: 09/06/2021 Aceito em: 08/11/2021 